\title{
Fluoroscopy-assisted thoracoscopic resection of pulmonary nodules after computed tomography-guided bronchoscopic metallic coil marking
}

Takanori Miyoshi, MD, PhD, Kazuya Kondo, MD, PhD, Hiromitsu Takizawa, MD, Koichiro Kenzaki, MD, Haruhiko Fujino, MD, PhD, Shoji Sakiyama, MD, PhD, and Akira Tangoku, MD, PhD

From the Department of Oncological and Regenerative Surgery, Institute of Health Biosciences, University of Tokushima Graduate School, Kuramoto-cho, Tokushima, Japan.

Received for publication May 2, 2005; revisions received Sept 5, 2005; accepted for publication Sept 15, 2005.

Address for reprints: Kazuya Kondo, MD, Department of Oncological and Regenerative Surgery, Institute of Health Biosciences, University of Tokushima Graduate School, Kuramoto-cho, Tokushima 770-8503, Japan(E-mail:kondo@clin.med.tokushimau.ac.jp).

J Thorac Cardiovasc Surg 2006;131:704-10 $0022-5223 / \$ 32.00$

Copyright (C) 2006 by The American Association for Thoracic Surgery

doi:10.1016/j.jtcvs.2005.09.019
Objective: To localize small and deeply situated pulmonary nodules during thoracoscopy with roentgenographic fluoroscopy, we developed a marking procedure that uses a metallic coil.

Methods: Nine patients underwent video-assisted thoracoscopic surgery for the removal of 11 pulmonary lesions. Fluoroscopy-assisted thoracoscopic surgery after computed tomography-guided bronchoscopic metallic coil marking was performed with an ultrathin bronchoscope, with simulation by means of virtual bronchoscopy. During thoracoscopy, a C-arm-shaped roentgenographic fluoroscope was used to detect the radiopaque nodules.

Results: The marking procedure took 15 to 60 minutes from insertion to removal of the bronchoscope. There were no complications from the marking, and all 11 nodules were easily localized by means of thoracoscopy. The metallic coil showed the nodules on the fluoroscopic monitor, which aided in nodule manipulation. Nodules were completely resected under thoracoscopic guidance, except in one case in which a minithoracotomy was performed at an early stage of the trial. The pathologic diagnosis was primary adenocarcinoma in 9 patients, pulmonary metastasis from colon cancer in 1 patient, and pulmonary lymph node in 1 patient. Two cases of bronchioloalveolar adenocarcinoma with an invasive component and a well-differentiated adenocarcinoma were converted to open thoracotomy to perform curative lobectomy.

Conclusions: In this pilot study computed tomography-guided transbronchial metallic coil marking with an ultrathin bronchoscope with virtual bronchoscopic simulation might be a useful method for the fluoroscopy-assisted thoracoscopic resection of pulmonary nodules.

$\mathrm{W}$

ith advances in computed tomography (CT), small pulmonary lesions previously unseen on chest radiographs are being increasingly detected. ${ }^{1}$ Among lesions less than $10 \mathrm{~mm}$ in size, a considerable number of malignancies have been reported. ${ }^{2}$ Diagnosis of these lesions by means of percutaneous or transbronchial biopsy is difficult because they are too small to be visualized. ${ }^{3}$ Therefore surgical resection is needed for a definitive diagnosis, and thoracoscopic wedge resection might be an appropriate procedure because it is less invasive than conventional thoracotomy. ${ }^{4}$ However, small lesions are difficult to detect without manipulating the visceral pleura during thoracoscopic surgery. Therefore marking the lesion is necessary for accurate thoracoscopic resection.

Although several marking techniques have been reported, ${ }^{5-8}$ they have associated complications and identification failures. The hook-wire method carries the risk of pneumothorax, pulmonary hemorrhage, and wire dislodgement from the lung before 


\section{Abbreviations and Acronyms \\ CT = computed tomography \\ FATS-CM = fluoroscopy-assisted thoracoscopic surgery after CT-guided bronchoscopic metallic coil marking \\ VB $=$ virtual bronchoscopy}

thoracoscopy is performed. Kobayashi and colleagues ${ }^{9}$ reported on a preoperative marking technique using barium sulfate injected through a bronchoscope under CT guidance, followed by fluoroscopy-assisted thoracoscopic wedge resection. Recent reports suggest that CT-guided transbronchial biopsy with an ultrathin bronchoscope with simulation by means of virtual bronchoscopy (VB) is useful for diagnosing small peripheral pulmonary lesions. ${ }^{10}$ This study describes the safety and reliability of fluoroscopy-assisted thoracoscopic surgery after CT-guided bronchoscopic metallic coil marking (FATS-CM) with an ultrathin bronchoscope, with simulation by means of VB.

\section{Patients and Methods}

Indications for FATS-CM are lesions that are difficult to identify by means of thoracoscopic examination, including (1) peripheral pulmonary lesions measuring $10 \mathrm{~mm}$ that are scheduled for thoracoscopic wedge resection, (2) deeply located nodules measuring between 0 and $30 \mathrm{~mm}$ from the pleural surface, and (3) groundglass opacity lesions without pleural change. Exclusion criteria for this method are (1) lesions with pleural changes, (2) deeply located nodules measuring more than $30 \mathrm{~mm}$ from the pleural surface, and (3) lesions that are palpable by using pulmonary forceps for thoracoscopic surgery. We obtained approval for this technique from the institutional review board at our institution. After obtaining informed consent, 9 patients underwent FATS-CM for 11 lesions between January 2003 and July 2004. They consisted of 2 male and 7 female patients, with an average age of 58.4 years and an age range of 26 to 80 years. Four lesions were detected by means of CT screening for the follow-up of other diseases, and 7 lesions were found during CT screening for a health survey. The 11 lesions could not be detected on chest radiographs, even by means of retrospective reexamination. Also, the pathology was not known for all lesions preoperatively. The average tumor size was $10 \mathrm{~mm}$, with a range of 5 to $17 \mathrm{~mm}$, and the average distance from the outer margin of the lesion to the nearest pleural surface was 8.5 $\mathrm{mm}$, with a range of 0 to $15 \mathrm{~mm}$. Eight of the 11 lesions showed ground-glass opacity on thin-section CT.

\section{Virtual Bronchoscopy}

CT scan examinations were performed with a multidetector CT scanner (Aquilion; Toshiba, Tokyo, Japan) with the following parameters: collimation of $0.5 \mathrm{~mm}, 4$ detectors, pitch of 5 to 7 , and rotation time of 0.5 seconds. Helical volume data sets were acquired during single breath-hold inhalations. Images were then reconstructed from helical CT scans and transferred to a computer workstation (Alatoview, Toshiba, or Virtual Place worksite, Med- ical Imaging Laboratory, Tokyo, Japan). All VB images were made by one radiologist. A volume-rendering method was used for the VB algorithm. VB objects were constructed by means of autosegmentation, and a fly-through image was used. Reconstructed VB images were accurately generated to approximately the sixth degree of bronchi (Figure 1).

\section{Localization Technique}

One endoscopist and one assistant were necessary for this procedure. An endoscopist performed the preoperative localization in a room equipped with a CT system (W3000AD, X-ray CT System; Hitachi Corp, Tokyo, Japan). The procedure was basically the same as previously reported. ${ }^{9}$ First, the anatomic location of the target lesion was examined by means of thin-section CT with 1-mm collimation. Then VB imaging was used to simulate the branches of the bronchus leading to the lesions, after which thin videobronchoscopes (BF type XP40 and BF type XP260F; Olympus Optical Co, Ltd, Tokyo, Japan) with a $2.8-\mathrm{mm}$ distal rigid portion diameter were used. The bronchoscopes were orally inserted after achievement of local anesthesia, and the tracheobronchial lumen was examined. Next, a transbronchial coil-feeding catheter (Boston Scientific Japan Co, Ltd, Tokyo, Japan) was inserted into the target bronchus and fluoroscopically guided to the possible lesion site, which was then assessed by means of highresolution CT before the procedure. The coil-feeding catheter was prepared by inserting a guiding wire into the catheter. When the patient was placed into the $\mathrm{CT}$ scanner, the bronchoscope was inserted in the mouth, and the 3-dimensional relationship between the lesion and the tip of the coil-feeding catheter was assessed by means of high-resolution CT with 2-mm collimation. When the tip of the coil-feeding catheter reached its target, a fibered platinum coil (Boston Scientific Japan Co, Ltd, Tokyo, Japan) was instilled into the bronchus under CT fluoroscopic guidance. 9 Subsequently, the 3-dimensional relationship between the coil marker and the lesion was made with high-resolution CT. The procedure was completed after fluoroscopically confirming the clarity of the metallic coil marker (Figure 2).

\section{Thoracoscopic Resection Technique}

The interval between marking and the operation depended on the operation schedule because an intrabronchial coil marking is almost permanent. A similar coil used for blood vessel embolism was used endobronchially for this study. This coil was not harmful to the human body. It was rare for these coils to migrate because of coughing because we detained these markers to the peripheral lung, and these markers took on the shape of coil in the tip of the bronchus. Each patient was given general anesthesia with a double-lumen tube and placed in a lateral position. After initiating single-lung ventilation, a thoracoscope was inserted through a trocar in the seventh intercostal space in the midaxillary line. Additional trocar insertion or minithoracotomy of less than $5 \mathrm{~cm}$ in length was performed at appropriate sites after equipping a $\mathrm{C}$-armshaped portable fluoroscopic unit. The nodule with coil markings was grasped with forceps and resected with endostaplers under fluoroscopic and thoracoscopic guidance (Figure 3). The specimen was immediately examined to determine the completeness of the resection and then sent to a pathologist. 


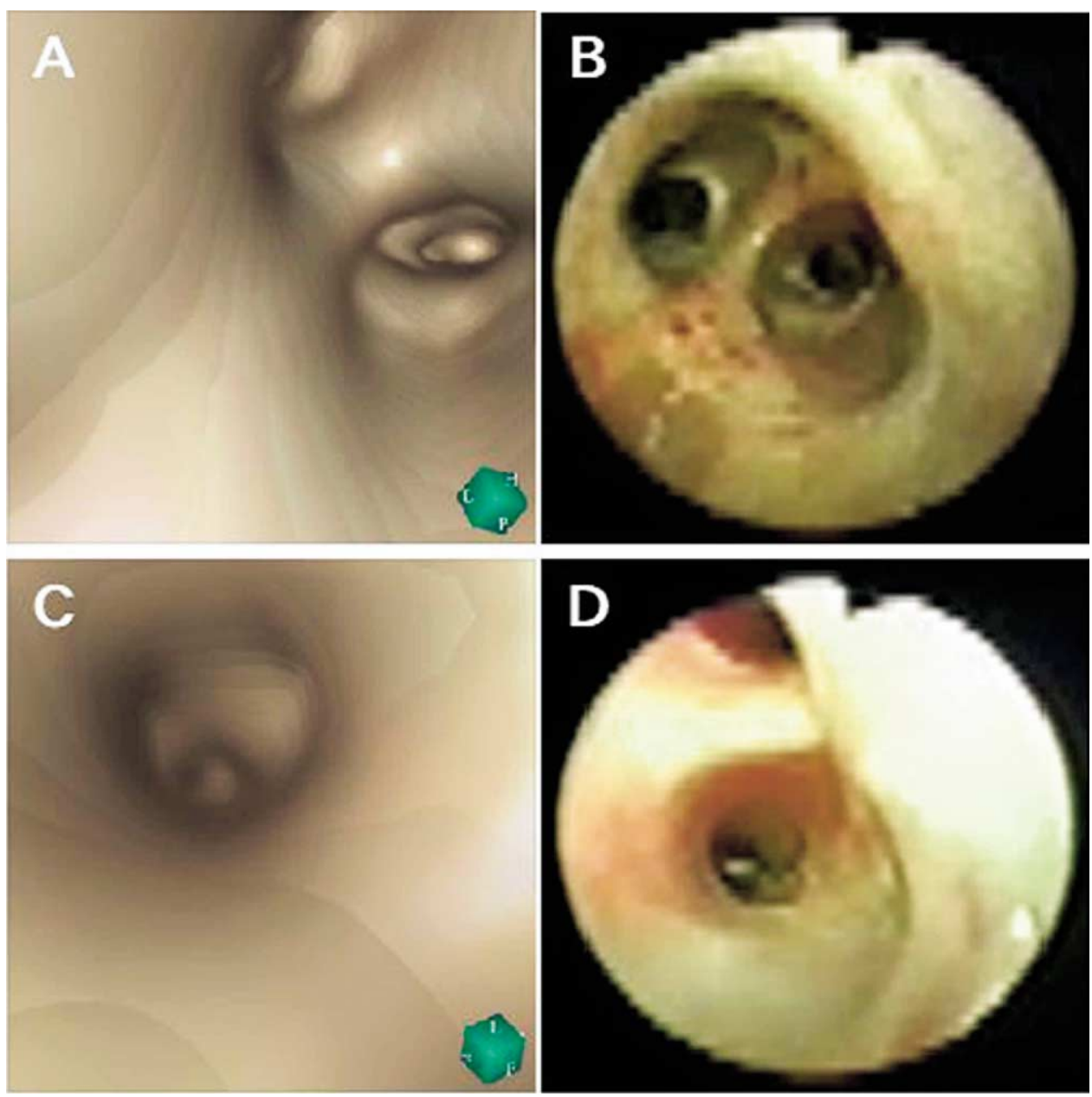

Figure 1. An example of bronchi seen on virtual bronchoscopic images (left) and ultrathin bronchoscopy (right). $A$ and $B$, Right B4a, b; C and D, right B4aii $\alpha, \beta$.

For these procedures, one surgeon, one thoracoscopist, and one fluoroscopist were needed at minimum. Furthermore, the bronchoscopist and the surgeon were the same person. There were 2 surgeons who participated in the study (TM and KK).

\section{Results}

The marking procedure from insertion to removal of the bronchoscope took from 15 to 60 minutes for each case, with a mean procedure time of 32 minutes (Table 1). In these cases surgical excision was necessary because of the preoperative CT findings, for example for primary lung cancer, and then a preoperative biopsy was not performed. No complications during the marking procedure or for the coil marker itself were noted. All coil markers were stable until surgical intervention because reevaluation by means of CT scanning confirmed that they had not moved. The total cost, including bronchoscopy, for localization in addition to the metallic coils was about US \$400. The lesions were resected from 1 to 30 days after coil marking, with a mean interval of 7 days. Ten resections were performed with 3 thoracoports, and one was carried out with a single port combined with a minithoracotomy. Minithoracotomy was only performed during the early stage of the trial. The nodule was solid on the visceral pleural surface, and we performed minithoracotomy to palpate the lesion in an early pilot study. At present, all resections are performed with 3 ports. All 11 lesions showed no changes on the visceral pleura related to the lesion or marking. Nine of 11 lesions were less than or equal to $1 \mathrm{~cm}$ from the visceral pleural surface in this early pilot study. All the lesions were identified as a coil nodule on fluoroscopic imaging and resected with sufficient margins. The mean fluoroscopic exposure time was 5 minutes. Resection of the nodules required 58 minutes on average, with a range of 25 to 95 minutes from incision to removal of the specimen. The average intraoperative blood 


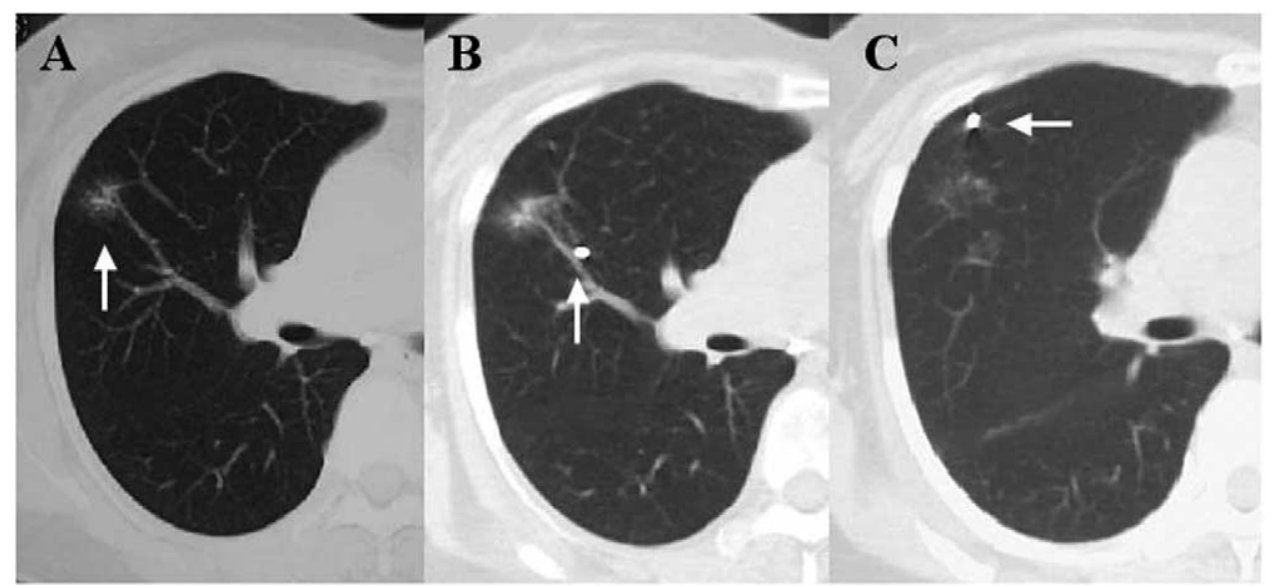

Figure 2. A, Chest CT scan before marking. The lesion (arrow), $12 \mathrm{~mm}$ in size and $6 \mathrm{~mm}$ in depth from the visceral pleura, is located in the right middle lobe. B, Chest CT after marking. A metallic coil (arrow) is detained on the central side of the lesion. C, Chest CT after marking. A metallic coil (arrow) is detained on the distal side of the lesion.

loss was $20 \mathrm{~mL}$, with a range of 10 to $60 \mathrm{~mL}$. Thoracoscopic wedge resection was performed on all patients without any complications. Two cases of adenocarcinoma diagnosed by using frozen sections were converted to an open thoracot- omy with a 10-cm skin incision to perform a curative lobectomy (case 7, Figure 4). Pathologic examinations revealed that the 11 lesions were primary adenocarcinoma in 8 patients, pulmonary metastasis from colon cancer in 1 pa-
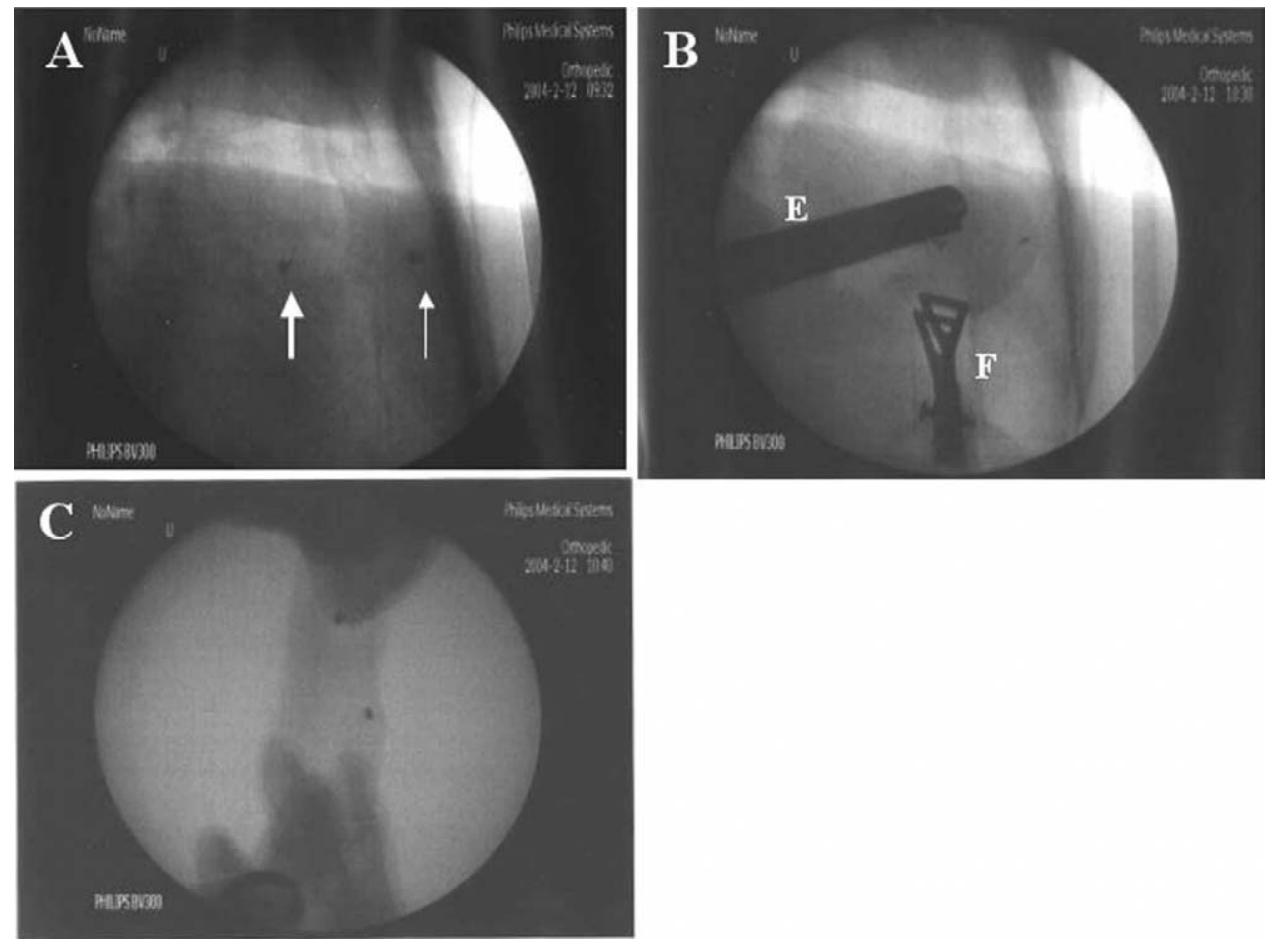

Figure 3. The same patients as in Figure 1. A, Intraoperative fluoroscopic imaging. A metallic coil (arrow) is detained on the central side of the lesion, and another coil (thin arrow) is detained on the distal side of the lesion. B, The nodule with metallic coil marking, which is grasped with the pulmonary forceps, is resected by endostaplers under both fluoroscopic and thoracoscopic guidance. C, Since the markers are located on the central and distal sides of the lesion, resection of the markers means complete removal of the lesion. (E: Endostapler; $F$ : pulmonary forceps.) 
TABLE 1. Characteristics of the patients

\begin{tabular}{|c|c|c|c|c|c|c|c|c|c|c|c|}
\hline $\begin{array}{c}\text { Patient } \\
\text { no. }\end{array}$ & Age & Sex & $\begin{array}{l}\text { Tumor } \\
\text { size } \\
(\mathbf{m m})\end{array}$ & $\begin{array}{l}\text { Distance } \\
\text { from } \\
\text { pleura } \\
\text { (mm) }\end{array}$ & $\begin{array}{c}\text { Tumor } \\
\text { characteristics }\end{array}$ & $\begin{array}{c}\text { Time of } \\
\text { marking } \\
\text { procedure } \\
\text { (min) }\end{array}$ & $\begin{array}{l}\text { No. of } \\
\text { marking } \\
\text { coils }\end{array}$ & $\begin{array}{c}\text { Days from } \\
\text { marking to } \\
\text { resection }\end{array}$ & $\begin{array}{c}\text { Histology } \\
\text { (Noguchi's } \\
\text { classification) }\end{array}$ & Surgical procedure & $\begin{array}{l}\text { Time of } \\
\text { partial } \\
\text { resection } \\
\text { (min) }\end{array}$ \\
\hline 1 & 58 & $\mathrm{~F}$ & 7 & 10 & Solid & 46 & 1 & 1 & Pulmonary LN & VATS & 68 \\
\hline 2 & 78 & M & $8,8,10$ & $5,10,8$ & GGO & 60 & $\begin{array}{c}3 \\
\text { (3 lesions) }\end{array}$ & 1 & LBAC $\times 3(A)$ & VATS & 95 \\
\hline 5 & 26 & $\mathrm{~F}$ & 5 & 10 & GGO & 26 & 1 & 2 & $\operatorname{LBAC}(\mathrm{A})$ & VATS & 52 \\
\hline 6 & 44 & $\mathrm{~F}$ & 12 & 8 & GGO & 23 & 1 & 7 & LBAC (B) & VATS & 67 \\
\hline 7 & 58 & $\mathrm{~F}$ & 12 & 7 & GGO & 27 & 2 & 7 & $\begin{array}{l}\text { LBAC with } \\
\text { IC (C) }\end{array}$ & VATS $\rightarrow$ lobectomy & 25 \\
\hline 8 & 72 & $\mathrm{~F}$ & 17 & 10 & GGO & 20 & 2 & 7 & W/D Ad (C) & VATS $\rightarrow$ lobectomy & 44 \\
\hline
\end{tabular}

$L N$, Lymph node; VATS, video-assisted thoracoscopic surgery; GGO, ground-glass opacity; $L B A C$, localized bronchioloalveolar adenocarcinoma; IC, invasive component; $W / D A d$, well-differentiated adenocarcinoma; Meta, metastatic tumor from colon cancer.

tient, and pulmonary lymph node in 2 patients. Margins more than or equal to $10 \mathrm{~mm}$ from the tumors to the resection lines were not cancer cells on the basis of frozen sections in all cases. Therefore re-excision was not needed in all cases. There was no difficultly in making a pathologic diagnosis with metallic coil detection. Of the 6 patients with primary lung cancer, 4 had localized bronchioloalveolar adenocarcinoma without an invasive component. All of these lesions were type A or B by means of Noguchi's classification. ${ }^{11}$ On the basis of the excellent prognosis for this type of adenocarcinoma, ${ }^{11}$ the patients were followed up instead of performing a complete lobectomy. The remaining 2 patients were given diagnoses of localized bronchioloalveolar adenocarcinoma with an invasive component and well-differentiated adenocarcinoma. These lesions were type C by Noguchi's classification. These 2 patients subse- quently underwent curative lobectomy. The chest tube was removed after 2 postoperative days on average, with a range of 1 to 4 days. There was no recurrence in all 7 patients with primary lung cancer after an average follow-up of 370 days and range of 150 to 545 days.

\section{Discussion}

Thoracoscopic resection is a useful procedure for diagnosing indeterminate pulmonary nodules with regard to safety and accuracy. ${ }^{4}$ However, the most common cause of conversion from thoracoscopic resection to open thoracotomy is failure to identify the lesion. ${ }^{4}$ Suzuki and associates ${ }^{12}$ reported that thoracoscopic identification is impossible in cases in which lesions of $10 \mathrm{~mm}$ or less are located more than $10 \mathrm{~mm}$ deep from the pleura. The average size and depth of the lesions in this study was 10 and $8.5 \mathrm{~mm}$, respec-
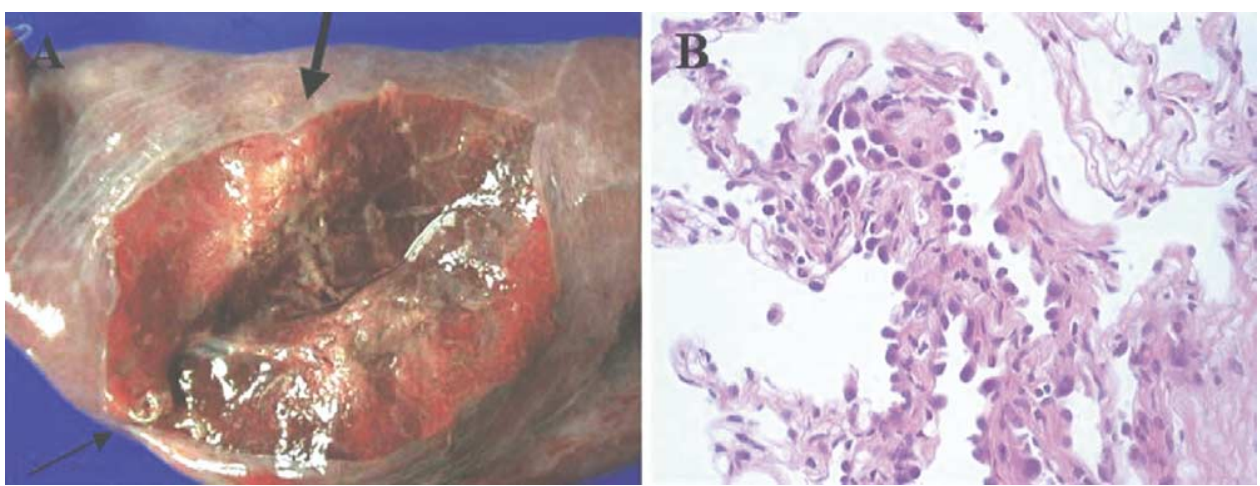

Figure 4. A, Macroscopic findings of the resected tumor specimen showing a white-gray tumor (arrow) and metallic coil (thin arrow). B, The histopathologic appearance of the resected specimen showing bronchioloalveolar adenocarcinoma. (Hematoxylin and eosin stain; original magnification $400 \times$ ). 
tively. We could not identify all of the lesions by means of thoracoscopic inspection alone because most were too small and radiographically faint, which meant that they were not so solid, even by palpation.

Several marking techniques for the thoracoscopic resection of small pulmonary nodules have been reported. We reviewed representative reports for failure of identification and complications. In transthoracic hook-wire injection, wire dislodgement occurs in $4 \%$ to $20 \%$ of cases, and failure of intraoperative identification occurs in $0 \%$ to $5 \% .{ }^{5,13-15}$ In localization by dye injection, failure of intraoperative identification occurs in $0 \%$ to $7 \%$ of cases because of dye diffusion or severe anthracosis of the visceral pleura. ${ }^{6,16}$ For these needling techniques, pneumothorax occurs in $4 \%$ to $50 \%$ of cases. In addition, there are some latent possibilities of implantation along the needle tract ${ }^{17}$ and fatal air embolization. ${ }^{18,19}$ With regard to pathologic examination, an injected marker or secondary hematoma caused by these procedures might disturb the diagnosis of complicated cases. Although intraoperative ultrasonography is safe, it is difficult to detect small and radiographically faint lesions by using this procedure. In patients with obstructive lung disease, such as emphysema, completely deflating the lung is difficult. In such cases intraoperative ultrasonography might be limited. ${ }^{8}$ Some studies reported on a marking technique involving the use of barium sulfate ${ }^{20}$ or lipiodol, ${ }^{21}$ followed by thoracoscopic resection under fluoroscopic guidance. We have developed a new marking technique that uses a metallic coil followed by thoracoscopic resection under fluoroscopic guidance.

In addition, we applied this procedure to 11 lesions in 9 patients with small peripheral pulmonary lesions and confirmed its safety and reliability. Furthermore, the marking procedure does not need to be coordinated with the operating room schedule. In our procedure a metallic coil is administered through the transbronchial route to avoid complications, such as pneumothorax, secondary hematoma, and the intravascular injection of substances originating in needling, and then this procedure is applicable to lesions located near the interlober or mediastinal region, as well as multiple or bilateral lesions. Because the single metallic coil was located central to the lesion under CT guidance, we could resect the lesion with a sufficient surgical margin. The coil on the central side of the tumor was held from the peripheral lung side with forceps. Margins more than or equal to 10 $\mathrm{mm}$ from the tumors to the resection lines were not cancer cells on the basis of frozen sections in all cases. Therefore re-excision was not needed in all cases. Furthermore, damage to specimens resulting from marking, resecting, or both is minimal. This marking procedure is advantageous over needling procedures in the diagnosis of small and subtle lesions.
Recently, we successfully obtained VB images from helical CT scan information and used them to simulate and navigate appropriate bronchial routes to small peripheral pulmonary lesions. Several groups have reported using VB images for the simulation of major endobronchial abnormalities $^{22}$ and for the assessment of tracheobronchial steno$\operatorname{sis}^{23}$ and bronchial malignant disease. ${ }^{24}$ To navigate cases of thoracic disease, others have used VB images for guidance during transbronchial aspiration biopsies of mediastinal lymph nodes. ${ }^{25,26}$ For peripheral lesions, Moriya and colleagues ${ }^{27}$ reported using VB images as a guide for conventional transbronchial biopsy. Furthermore, Asano and coworkerrs ${ }^{10}$ reported a case of small peripheral pulmonary lesions diagnosed by using ultrathin bronchoscopy with VB imaging for bronchoscopic navigation. In cases of transbronchial biopsy with an ultrathin bronchoscope, the bronchoscopists have to explore many bronchi to reach the lesions, and patients might not tolerate such a lengthy procedure. Although high-resolution CT scanning can be used to determine the optimal bronchial path to the lesions, a 3-dimensional understanding of the complicated bronchial bifurcation on the basis of axial images is difficult. In this study VB images were made by a radiologist, but with further technologic developments, respiratory surgeons and bronchologists will be able to make VB images from information obtained by using helical CT scanning.

On the other hand, the total cost, including bronchoscopy, for localization in addition to the metallic coils was about US \$400. In particular, the high cost of about US \$200 for the metallic coil is a disadvantage. Once an exclusiveuse coil is developed, lower costs might result. We are currently developing a coil exclusively for marking in cooperation with a commercial company and confirming its safety in animal experiments with a pig model. Also, preparations for clinical trials are underway. This coil is expected to cost about US \$15.

The limitation of this technique was that this technique might not be applicable for lesions near the hilum of the lung. The potential complications of the procedures are metallic allergy to the metallic coil and its migration. We prevented metallic allergy by obtaining the allergic history of the patient beforehand. Also, when the lesion was near the hilum of the lung, we gave up the coil instillation and thus could prevent against migration of the coil.

In summary, in this pilot study CT-guided transbronchial metallic coil marking with an ultrathin bronchoscope with VB stimulation was found to be feasible and safe. It might be a useful method not only for making a diagnosis but also for therapeutic wedge resection in selected early lung cancers.

We thank Professor J. Ueno (Department of Radiology, School of Health Sciences, University of Tokushima) for radiologic analysis and helpful discussion. 


\section{References}

1. Kaneko M, Eguchi K, Ohmatsu H, Kakinuma R, Naruke T, Suemasu $\mathrm{K}$, et al. Peripheral lung cancer: screening and detection with low-dose spiral CT versus radiography. Radiology. 1996;201:798-802.

2. Munden RF, Pugatch RD, Liptay MJ, Sugarbaker DJ, Le LU. Small pulmonary lesions detected at CT: clinical importance. Radiology. 1997;202:105-10.

3. Li H, Boiselle PM, Shepard JO, Trotman-Dickenson B, McLoud TC. Diagnostic accuracy and safety of CT-guided percutaneous needle aspiration biopsy of the lung: comparison of small and large pulmonary nodules. Am J Radiol. 1996;167:105-9.

4. Hazelrigg SR, Nunchuck SK, LoCicero J 3rd. Video Assisted Thoracic Surgery Study Group data. Ann Thorac Surg. 1993;56:1039-43.

5. Mack MJ, Shennib H, Landreneau RJ, Hazelrigg SR. Techniques for localization of pulmonary nodules for thoracoscopic resection. J Thorac Cardiovasc Surg. 1993;106:550-3.

6. Wicky S, Mayor B, Cuttat JF, Schnyder P. CT-guided localizations of pulmonary nodules with methylene blue injections for thoracoscopic resections. Chest. 1994;106:1326-8.

7. Nomori H, Horio H. Colored collagen is a long-lasting point marker for small pulmonary nodules in thoracoscopic operations. Ann Thorac Surg. 1996;61:1070-3.

8. Greenfield AL, Steiner RM, Liu JB, et al. Sonographic guidance for the localization of peripheral pulmonary nodules during thoracoscopy. Am J Radiol. 1997;168:1057-60.

9. Kobayashi T, Kaneko M, Kondo H, et al. CT-guided bronchoscopic barium marking for resection of a fluoroscopically invisible peripheral pulmonary lesion. Jpn J Clin Oncol. 1997;27:204-5.

10. Asano F, Matsuno Y, Matsushita T, et al. Transbronchial diagnosis of a pulmonary peripheral small lesion using an ultrathin bronchoscope with virtual bronchoscopic navigation. $J$ Bronchol. 2002;9:108-11.

11. Noguchi M, Morikawa A, Kawasaki M, et al. Small adenocarcinoma of the lung. Histologic characteristics and prognosis. Cancer. 1995; $75: 2844-52$.

12. Suzuki K, Nagai K, Yoshida J, et al. Video-assisted thoracoscopic surgery for small indeterminate pulmonary nodules: indications for preoperative marking. Chest. 1999;115:563-8.

13. Shepard JA, Mathisen DJ, Muse VV, Bhalla M, McLoud TC. Needle localization of peripheral lung nodules for video-assisted thoracoscopic surgery. Chest. 1994;105:1559-63.
14. Gossot D, Miaux Y, Guermazi A, Celerier M, Friga J. The hook-wire technique for localization of pulmonary nodules during thoracoscopic resection. Chest. 1994;105:1467-9.

15. Kanazawa S, Ando A, Yasui K, et al. Localization of pulmonary nodules for thoracoscopic resection: experience with a system using a short hookwire and suture. Am J Radiol. 1998;170:332-4.

16. Vandoni RE, Cuttat JF, Wicky S, Suter M. CT-guided methyleneblue labelling before thoracoscopic resection of pulmonary nodules. Eur J Cardiothorac Surg. 1998;14:265-70.

17. Voravud N, Shin DM, Dekmezian RH, Dimery I, Lee JS, Hong WK. Implantation metastasis of carcinoma after percutaneous fine-needle aspiration biopsy. Chest. 1992;102:313-5.

18. Cianci P, Posin JP, Shimshak RR, Singzon J. Air embolism complicating percutaneous thin needle biopsy of lung. Chest. 1987;92: 749-51.

19. Sakiyama S, Kondo K, Matsuoka H, et al. Fatal air embolism during computed tomography-guided pulmonary marking with a hook-type marker. J Thorac Cardiovasc Surg. 2003;126:1207-9.

20. Okumura T, Kondo H, Suzuki K, et al. Fluoroscopy-assisted thoracoscopic surgery after computed tomography-guided bronchoscopic barium marking. Ann Thorac Surg. 2001;71:439-42.

21. Nomori H, Horio H, Naruke T, Suemasu K. Fluoroscopy-assisted thoracoscopic resection of lung nodules marked with lipiodol. Ann Thorac Surg. 2002;74:170-3.

22. Vining DJ, Liu K, Choplin RH, Haponik EF. Virtual bronchoscopy. Chest. 1996;109:549-53.

23. Hoppe H, Walder B, Sonnenschein M, Vock P, Dinkel HP. Multidetector CT virtual bronchoscopy to grade tracheobronchial stenosis. Am J Radiol. 2002;178:1195-200.

24. Finkelstein SE, Summers RM, Nguyen DM, Stewart JH 4th, Tretler JA, Schrump DS. Virtual bronchoscopy for evaluation of malignant tumors of the thorax. J Thorac Cardiovasc Surg. 2002;123:967-72.

25. McAdams HP, Goodman PC, Kussin P. Virtual bronchoscopy for directing transbronchial needle aspiration of hilar and mediastinal lymph nodes: a pilot study. Am J Radiol. 1998;170:1361-4.

26. Hopper KD, Lucas TA, Gleeson K, et al. Transbronchial biopsy with virtual CT bronchoscopy and nodal highlighting. Radiology. 2001; 221:531-6.

27. Moriya H, Koyama M, Honjo H, Shishido F. Interactive virtual bronchoscopy as a guide for transbronchial biopsy in two cases. J Jpn Soc Bronchol. 1998;20:610-3. 